The patient showed some features common to $\mathrm{C} 2$ deficiency related nephropathy, ${ }^{2}$ but lacked the usual histological features.

PAPS criteria $^{5}$ were fulfilled by our patient; he had a history of thrombosis and a moderate level of anticardiolipin antibodies without a primary cause. The association of antiphospholipid antibodies with thromboembolic disorders is well established. ${ }^{67}$ In accordance with these reports, we believe that the existence of these antibodies in our patient increased the risk of cerebral ischaemic events, evidence of which was already present in the grossly dilated vertebrobasilar anomaly. Here, renal disease seemed not to be directly related to antiphospholipid antibodies because thrombotic microangiopathy was not demonstrated. ${ }^{8}$

Antiphospholipid antibodies have already been related to the presence of null alleles of C4 in patients with systemic lupus erythematosus, ${ }^{9}$ but not in PAPS patients. ${ }^{10}$

The basis for the association between inherited complement deficiency of early components and autoimmune disease is not understood. It may involve ineffective clearance of microbial or non-infectious antigens (such as cardiolipin) which might stimulate autoantibodies. In our patients, because of the rarity of homozygous C2 deficiency, it is likely that this condition was causally related to the antiphospholipid syndrome.

M R JULIA

N MATAMOROS

J MILÀ

Immunology Section, Hospital Son Dureta

X BESTARD

J GASCO

Nephrology Section, Hospital Son Dureta

G AMER

Neurology Section, Hospital Son Dureta

Correspondence to: $\mathrm{Dr} N$ Matamoros, c/Andrea Doria 55, 07014 Palma de Mallorca, Balearic Islands, Spain.

We thank Dr A D B Webster for helpful discussions on the manuscript, and Dr A Corell for complotype studies.

1 WHO Scientific Group on Immunodeficiency. Primary immunodeficiency diseases report. Immunodef Rev 1992; 3: 195-236.

2 Rynes R, Pickering R J. Inherited complemen component deficiencies in man. In Whaley $\mathrm{K}$ ed. Methods in complement for clinical immunologists. New York: Churchill Livingstone, 1985; 292-321.

3 Harris E N. The Second International AntiCardiolipin Standardization Workshop/The Kingston Anti-Phospholipid Antibody Study (KAPS) Group. Am $\mathcal{F}$ Clin Pathol 1990; 94: 476-83.

4 Johnson C H A, Densen P, Wetsel R A Cole F S, Goeken N E, Colten H R. Molecular heterogeneity of C2 deficiency. $N$ Engl f Med 1992; 326: 871-4

5 Asherson R A, Khamashta M A, Ordi-Ros J, et al. The 'Primary' antiphospholipid syndrome: major clinical and serological features. Medicine 1989; 68: 366-74

6 Brey R L, Hart R G, Sherman D G, Tegeler C $\mathrm{H}$. Antiphospholipid antibodies and cerebral ischemia in young people. Neurology 1990; 40: 1190-6.

7 Asherson $R$ A, Khamashta $M$ A, Gil A, et al. Cerebrovascular disease and antiph, et al. Cerebrovascular disease and antiphospholipid antibodies in systemic lupu erythematosus, lupus-like disease, and the primary antiphospholip 1989; 86: 391-9.

8 Amigo M C, Garcia-Torres $R$, Robles $M$ Bochicchio T, Reyes P A. Renal involvement in primary antiphospholipid syndrome.

9 Wilson W A, Perez M C, Michalsski J P, Armatis P E. Cardiolipin antibodies and nul alleles of $\mathrm{C} 4$ in black American with systemic lupus erythematosus. $\mathcal{F}$ Rheumatol 1988; 15: 1768-72.
10 Asherson R A, Doherty D G, Vergani D, Khamashta M A, Hughes G R V. Major histocompatibility complex associations with primary antiphospholipid syndrome. Arthritis Rheum 1992; 35: 124-5.

\section{Might patients with HLA-B27 related diseases benefit from antiandrogenic treatment?}

There are several rheumatic diseases which may be suspected of sharing the curious feature that both probands and their unaffected sibs have sex ratio biases that are in the same direction. For instance, rheumatoid arthritis (RA), early onset pauciarticular juvenile rheumatoid arthritis, and coxarthrosis are all conditions in which probands and their unaffected sibs seem to contain excesses of females, while ankylosing spondylitis (AS), Reiter's syndrome, and late onset pauciarticular juvenile rheumatoid arthritis are all conditions in which probands and their unaffected sibs seem to contain excesses of males. ${ }^{12}$ The caution in the foregoing sentence is appropriate, because many of the data underlying these conclusions were gathered for other purposes and were therefore subject to possible volunteer bias or survivorship bias (both of which would be expected to lead to female excesses). However, these qualifications do not apply to the data on juvenile rheumatoid arthritis; ${ }^{2}$ and they do not apply to recent reports of data explicitly gathered to test the sex ratio biases of sibs of RA and AS probands. ${ }^{3-6}$ Tables 1 and 2 summarise these data; they suggest that the biases are real.

What may be inferred from this? One may propose that the same agent causes both the disease in probands and the unusual sex ratios in their unaffected sibs.

There is very substantial evidence that parental hormone levels at the time of conception partially control the sexes of human offspring at birth. ${ }^{7}$ So I suggested that low testosterone levels are a cause of RA and of RA patients' excess of sisters, and that high testosterone levels are a cause of AS and of these probands' excess of brothers. ${ }^{1}$ The suspicion in regard to RA was strengthened by the subsequent demonstration that $\mathrm{RA}$ patients may benefit from androgen treatment. ${ }^{9}$ So the question arises if patients with HLA-B27 related diseases might, analogously, benefit from antiandrogen treatment. This resolves into the question: what evidence is there that HLA-B27 related diseases are partially caused by high levels of androgens?

For illustrative purposes, I shall consider AS (because there are more published data on this condition), but the following speculations may also apply to the other B27 related diseases. It is well established that patients with AS have high testosterone levels, on average. ${ }^{10-12}$ Moreover, there is evidence that B27 is associated with high testosterone levels in healthy controls also. ${ }^{1} 13$ Thus the high testosterone levels in AS patients may reasonably be interpreted as a genetically determined precursor of the disease, rather than its consequence. This conclusion is strengthened by the observation that disease, in general, causes men's testosterone levels to decrease, not increase. ${ }^{14}$
Table 1 Recently published data on the sexes of sibs of probands with ankylosing spondylitis

\begin{tabular}{lll}
\hline Source & Brothers & Sisters \\
\hline Calin et al $^{3}$ & 232 & 199 \\
Ploski al $^{4}$ & 54 & 32 \\
Totals & 286 & 231 \\
\hline
\end{tabular}

Tested against an expected white live birth sex ratio of $0.514,5$ the pooled data here yield a $\chi^{2}$ value of $3.2(p<0.05$, one way)

Table 2 Recently published data on the sexes of the sibs of probands with rheumatoid arthritis

\begin{tabular}{|c|c|c|}
\hline Source & Brothers & Sisters \\
\hline Calin $e t a l^{3}$ & 280 & 294 \\
\hline Ploski et al ${ }^{4}$ & 191 & 210 \\
\hline Deighton et $a l^{6}$ & 36 & 46 \\
\hline Totals & 507 & 550 \\
\hline
\end{tabular}

Tested against an expected white live birth sex ratio of $0.514,5$ the pooled data here yield a $\chi^{2}$ value of 5.0 ( $p<0.02$, one way)

So there seem to be good grounds for supposing that some of the sex related rheumatic diseases are caused by unusual hormone levels which in turn are (partially) controlled by their associated HLA antigens. Accordingly, it seems reasonable to wonder if AS patients might benefit from antiandrogenic treatment.

This raises a moral problem which is illustrated in the predicament of the television playwright, the late Dennis Potter. His suffering from psoriatic arthritis (a B27 related condition) was dramatised in The Singing Detective. One may suggest that Potter's creativity and pervasive interest in sex may both have had a hormonal basis. Practitioners offering antiandrogen treatment should advise patients of their possible psychological side effects. Men who want relief from their B27 related diseases may nevertheless not be keen to risk compromising their masculinity in the process; so it might be preferable to consider treating female patients first.

WILLIAM H JAMES
The Galton Laboratory,
University College London,
Wolfson House,
London NW1 $2 \mathrm{HE}$,
United Kingdom

1 James W H. Sex ratios and hormones in HLA related rheumatic diseases. Ann Rheum Dis 1991; 50: 401-4

2 Aaron S, Fraser P A, Jackson J M, Larson M, Glass D N. Sex ratio and sibship size in juvenile rheumatoid arthritis kindreds. juvenile rheumatoid 28: 753-8.

3 Calin A, Garrett S L, Hirst S, Kennedy L G. A controlled prospective study of the sex ratios among relatives of patients with HLA related diseases: distinct patterns in ankylosrelated diseases: distinct patterns in ankylosing spondylitis and sero negative rheumatoid 63.

4 Ploski R, Kvien T, Vinje O, Rønningen $K$, Forre Ø. Altered sex ratio of siblings of patients with rheumatic diseases [abstract]. Arthritis Rheum 1994; 37 (suppl) S303.

5 James $W \mathrm{H}$. The human sex ratio. Part 1: review of the literature. Hum Biol 1987; 59: 721-52.

6 Deighton C M, Watson M, Walker D J Rheumatoid arthritis, sex ratio, HLA-DR and testosterone. Ann Rheum Dis 1993; 52: 244.

7 James W H. The human sex ratio. Part 2: a hypothesis and a program of research. Hum hiol 1987; 59: 873-900.

8 James W H. The hypothesized hormonal control of mammalian sex ratio at birth-a second update. 7 Theor Biol 1992; 155: 121-8

9 Cutolo M, Balleari E, Giusti M, Intra E Accardo $S$. Androgen replacement therapy in male patients with rheumatoid arthritis Arthritis Rheum 1991; 34: 1-5. 
10 Spector T D, Ollier W E R, Perry L A Silman A J, Thompson P W, Edwards A. Free and serum testosterone levels in 276 males: comparative study of rheumatoid arthritis, ankylosing spondylitis and healthy controls. Clin Rheumatol 1989; 8: 37-41.

11 Tapia-Serrano R, Jimenez-Balderas F J, Murrieta $S$, Bravo-Gatica $C$, Guerra $R$, Murrieta S, Bravo-Gatica C, Guerra $R$ Mintz G. Testicular function in active ankylosing spondylitis: therapeutic response to chorionic gonadotropin. $\mathcal{F}$ Rheumatol 1991 18: $841-8$

12 Gordon D, Beastall G H, Thomson J A Sturrock R D. Androgenic status and sexua function in males with rheumatoid arthritis and ankylosing spondylitis. $Q \mathcal{F} M e d 1986 ; 60$ : 671-9.

13 Ollier W, Spector T, Silman A, et al. Are certain HLA haplotypes responsible for low testosterone levels in males? Dis Markers 1989; 7 : rone levels

14 Semple C G. Hormonal changes in nonendocrine disease. $B M F$ 1986; 293: 1049-52.

\section{Asymmetric rheumatoid vasculitis in a hemiplegic patient}

In 1962, Thomson and Bywaters described the phenomenon of a unilateral rheumatoid arthritis occurring in a hemiplegic patient; ${ }^{1}$ Oblick subsequently described a simila sparing in a patient in whom the limbs had been paralysed as a result of poliomyelitis. ${ }^{2}$ This protection was initially explained by lack of use of the hemiplegic limb, sparing the joints. More recently, a neurogenic mechanism has been proposed. ${ }^{3}$

The case to be described is of rheumatoid vasculitis which largely spared the hemiplegic side-a phenomenon not described previously. It is suggested that the asymmetric distribution supports a neurogenic mechanism.

The patient, who suffered from an arteriopathy, had his first myocardial infarction at the age of 37 . A second infarct one year later was followed rapidly by a cerebrovascular accident, thought to arise from embolism of a left ventricular wall thrombus, seen on the echocardiogram. This resulted in a dense left hemiplegia. In 1988, at the age of 48 , he developed seropositive rheumatoid arthritis and presented with a predominance of right sided synovitis, involving the right hand, knee and ankle, although there was mild involvement of the left hemiplegic side. He was treated with Voltarol retard, sulphasalazine $1 \mathrm{~g}$ twice daily and chloroquine $250 \mathrm{mg}$ three times a week, which produced good disease control and a decrease in the erythrocyte sedimentation rate from 50 to $25 \mathrm{~mm} / 1 \mathrm{st} \mathrm{h}$. Radiographs of the hands, taken two years later, showed bilateral erosions; joint space loss was considerably greater on the right side.

In April 1994, at the age of 51, the patient presented with a predominantly right sided vasculitic rash involving his hand, arm, foot, thigh, and buttock, with vasculitic ulcers on his right thigh and buttock (figure). He had nail fold infarcts of the right fingers and toes. Peripheral pulses were present and equal; joints were not active. There was no evidence of peripheral neuropathy, and no fever. There had been no recent change in medication to suggest a drug induced aetiology. Urine analysis was negative. Immunological studies showed him to be negative to antinuclear factor, antineutrophil cytoplasmic antibodies, and lupus anticoagulant, but positive to La(SS-B) antibody. A skin biopsy demonstrated a leucocytoclastic vasculitis. $\mathrm{He}$ was treated with intermittent pulsed intravenous cyclophosphamide $15 \mathrm{mg} / \mathrm{kg}$ and prednisolone. The rash faded and healed over the first two weeks of treatment, and he made a good subsequent recovery.

Whilst one could explain the unilateral rheumatoid joint involvement in a hemiplegic patient in terms of joint sparing in the paralysed limb, this mechanism could not be evoked to explain the predominantly unilateral distribution of the vasculitis to the non-hemiplegic side as described in this patient. This may provide further support for a neurogenic mechanism.

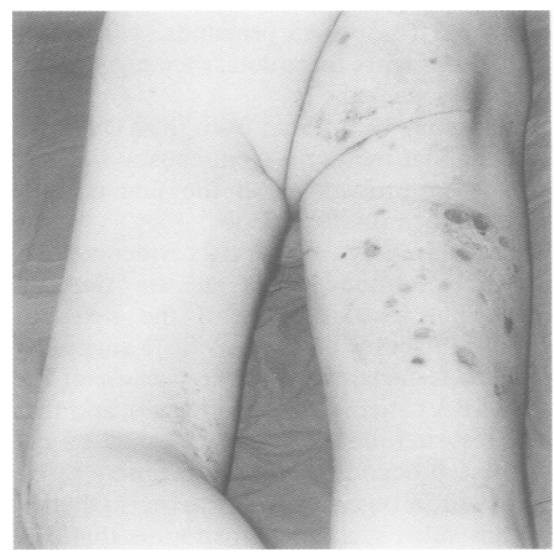

Asymmetric vasculitic rash on thigh.
Evidence for sensory nerve involvement in chronic arthritis comes from animal studies in which sectioning of the sciatic nerve seven days before the induction of adjuvant arthritis delayed the onset and severity of disease in the operated limb. ${ }^{4}$ Levine has suggested that neuromechanisms may also explain why rheumatoid arthritis is bilaterally symmetric. ${ }^{5}$ Evidence is growing that these effects are mediated through substance $\mathbf{P}$ in the sympathetic nervous system. ${ }^{6}$

The vasculitis in rheumatoid arthritis is predominantly small vessel and is caused by a precipitate of immune complex with subsequent polymorphic leucocyte infiltration. $^{7}$ Why the vasculitis should have occurred asymmetrically in this patient is unknown. There was no recent change in his medication to suggest a drug induced aetiology. The cerebrovascular accident predated the vasculitis by 10 years and was embolic; it was thus unlikely to have been the result of a single vascular process such as Sneddon's syndrome. One could speculate that alteration in vascular sympathetic tone in the hemiplegic $\operatorname{limb}^{8}{ }^{9}$ could decrease the local precipitation of immune complexes and thus explain the unilateral rheumatoid vasculitis described here.

\section{A L DOLAN \\ Department of Rheumatolog Greenwich District Hospital London SE10 9HE, United Kingdom}

1 Thomson M, Bywaters E G L. Unilateral rheumatoid arthritis following hemiplegia. Ann Rheum Dis 1962; 21: 370-7.

2 Glick E N. Asymmetrical rheumatoid arthritis after poliomyelitis. BMF 1967; iii: 26-9.

3 Kidd B L, Mapp P I, Blake D R, Gibson S J, Polak J M. Neurogenic influences in arthritis. Ann Rheum Dis 1990; 49: 649-52.

4 Courtright L J, Kuzzell W C. Sparing effects on neurological deficit and trauma on the course of adjuvant arthritis in the rat. Ann Rheum Dis 1965; 24: 360-7.

5 Levine J D, Collier D H, Basbaum A I, Moskowitz M A, Helms C A. The nervous system may contribute to the pathophysiology of rheumatoid arthritis. 7 Rheumatol 1985; 12. 406-11.

6 Garrett N E, Mapp P I, Cruwys S C, Kidd B $L$, Blake $D$. Role of substance $P$ in inflammatory arthritis. Ann Rheum Dis 1992; 51: 1014-8.

7 Scott D G I, Bacon P A, Tribe C R. Systemic rheumatoid vasculitis: a clinical and laboratory study of 50 cases. Medicine 1981;60 288-97.

8 Hachinski V C, Oppenheimer S M, Wilson J X, Guiraudon C, Cechetto D F. Asymmetry of sympathetic consequences of experimental stroke. Arch Neurol 1992; 49: 697-702.

9 Uncini A, DiMuzio A, Lugaresi A, Gambi D. Sympathetic skin response in hemispheric lesions. Neurophysiol Clin 1992; 22: 475-81. 